\title{
Usage of quality indicators in hospital nursing services in Brazil
}

\author{
Carmen Silvia Gabriel ${ }^{1}$, Daniele Ramos ${ }^{1}$, Andrea Boldrini ${ }^{1}$, Silvana Silveira Kempfer ${ }^{2}$, Andrea \\ Bernardes ${ }^{1}$, Fernanda Ludmila Rossi Rocha ${ }^{1}$ \\ 1. General and Specialized Nursing Department - Nursing school- Ribeirão Preto - University of São Paulo- USP, Brazil. \\ 2. Federal University of Santa Catarina-UFSC, Brazil. \\ Correspondence: Silvana Silveira Kempfer. Address: Jau Guedes da Fonseca, 292 ap 101 B - Coqueiros - Santa Catarina \\ - Brazil. Email: silvanakempfer@yahoo.com.br
}

Received: April 11, 2013

DOI : $10.5430 /$ jha.v2n4p91

Online Published: June 19, 2013

Accepted: June 6, 2013

\section{Abstract}

Quality indicators are tools to measure the quality of care.

Objective: To identify the quality indicators adopted by nursing services of hospitals in the state of São Paulo, Brazil.

Method: A cross-sectional, non-experimental, descriptive and quantitative approach, performed in seventeen teaching hospitals in the state of São Paulo, Brazil, using a questionnaire answered by the head of the Nursing Service.

Results: Only $5.9 \%$ of hospital nursing services do not adopt indicators, showing concern for the quality of care. There is a preference for the adoption of care indicators.

Conclusion: A culture of adoption and analysis of indicators exists in hospital nursing services and the indicators are related to classical nursing care processes, with less emphasis on the adoption of indicators related to human resource management and user satisfaction.

\section{Key words}

Quality indicators, Health care quality, Nursing services

\section{I ntroduction}

Ensuring the quality of health services basically means an effort to find and overcome problems, developing professionals, institutions and systems' performance and behavior towards more appropriate and acceptable practices in terms of health outcomes and costs ${ }^{[1]}$. Nevertheless, health service assessment can only be based on previously established criteria, standards and indicators.

In the nursing context, nurses should consider the continuous improvement of the quality of assistance as a dynamic and exhaustive process, in which the factors that affect the nursing team's work process are identified. This process requires systematic evaluation of the quality of care through fully developed by nursing professionals. Nurses need to analyze the results of care in order to (re)define management strategies, based on information that reflects the reality of healthcare ${ }^{[2]}$. 
As quality depends on different factors, there is no universal and comprehensive definition to be used for all health services. Quality means obtaining the best benefits with the lowest risks ${ }^{[3]}$. To evaluate the quality of health services, the main aspects to be considered are structure, process and outcome. Structure is related to the means by which care is rendered. The process is the way that care is provided. The outcome measures the improvement of patient health status ${ }^{[4]}$.

In the evaluation process, actions are needed based on indicators and parameters appropriate to each situation ${ }^{[5]}$. According to the Joint Commission on Accreditation of Healthcare Organizations, indicators measure the performance of functions, systems or processes, considering the condition or direction of the performance of a process or achievement of a target over time ${ }^{[6]}$.

As regards the development of indicators of nursing services, guiding axes need to be established, indicating the need to take into account healthcare, education and management policies, the organizational structure and the mission of the organization, as well as the work process, the human, materials and financial resources available and the customers' expectations. These factors are very important for nursing quality indicators and they should be clear, objective, measurable and useful, promoting the direction of quality improvements.

Different countries have implemented quality programs and accreditation processes of public or private health services to improve their performance and to reduce costs ${ }^{[7-9]}$. The World Health Organization underlines the development of clinical indicators focused on the monitoring of processes and outcomes, particularly in the hospital setting. Clinical indicators are considered to be data regarding the outcomes of health services, including complications, adverse events and readmissions ${ }^{[10]}$.

A Brazilian hospital association created a database of health quality indicators, including the nursing care indicators: incidence rates of falls and pressure ulcers; occurrence of nasogastric tube loss, phlebitis, non-compliance in medication administration and central catheter obstruction; hours of nursing training and the distribution of nurses and technicians per bed $^{[11]}$.

The use of databases between groups of hospitals has become a global trend. Successful experiences are highlighted, including the pioneering “Quality Indicator Project”, coordinated by the Maryland Hospital Association, in existence for over 20 years. Its goal is the continuous improvement of hospital care quality by comparing the quality indicators of hospitals distributed around the world ${ }^{[12]}$.

The Quality Indicator Project evaluates 45 indicators divided into subgroups, according to healthcare categories related to acute patients, long-term patients, psychiatric patients and home care. In general, the indicators refer to mortality, hospital infection, device use and unforeseen readmissions, while some are specifically related to nursing processes, such as falls and pressure ulcer indices, number of bedridden patients, patient satisfaction and training hours.

The Brazilian Accreditation Guideline is a tool created by the Organização Nacional de Acreditação to assess the quality of healthcare in Brazilian hospitals ${ }^{[13]}$. It does not specifically identify what indicators nursing services need to measure for quality of care, but does clearly assert that hospital services, including nursing services, should use indicators to analyze their performance.

Nurses recognize that the process indicators related to daily tasks performed by nurses are the most relevant to the quality of nursing care and highlight the quantitative and qualitative aspects that need to be evaluated in order to arrive at more precise evaluations of health assistance, exceeding the scope of their own processes ${ }^{[14]}$.

Considering the importance of the subject, the aim in this study was to identify the quality indicators adopted by nursing services of hospitals in São Paulo State, Brazil. 


\section{Method}

This is a descriptive, cross-sectional and non-experimental study with a quantitative data approach ${ }^{[15]}$. The study was conducted in teaching hospitals in the State of São Paulo. In the State of São Paulo, there are 891 hospitals, 166 of which are specialized hospitals, 725 general hospitals and 37 are teaching hospitals ${ }^{[16,17]}$. The sample consisted of all teaching hospitals; 17 hospitals were included that agreed to participate in this study, classified according to the type of institution (Table 1). All hospitals had more than 150 beds, and $11.7 \%$ had more than 500 beds.

Table 1. Type of hospitals in the State of São Paulo, 2012

\begin{tabular}{ll}
\hline Type of hospital & No. of hospitals \\
\hline General private & 4 \\
General public & 8 \\
Specialized private & 1 \\
Specialized public & 1 \\
Specialized non-for-profit private & 1 \\
General non-for-profit private & 2 \\
Total & $\mathbf{1 7}$ \\
\hline
\end{tabular}

Data were collected with a questionnaire constructed by the researchers based on a literature review about quality indicators for nursing services ${ }^{[18]}$. The questionnaire was sent by email to nurse coordinators of the selected hospitals. Three attempts were made to contact institutions that did not respond to the questionnaire within 15 days. Those hospitals that did not submit the questionnaire fifteen days after the third contact were excluded from the sample. After signing the Informed Consent Form, all nurse coordinators from the 17 institutions in São Paulo State responded to the instrument.

Before the start of the study, an expert panel of three judges evaluated the face and content validity of the questionnaire used. The self-applied questionnaire consists of 11 open and closed questions, alternating between dichotomous and multiple-choice, related to data that characterize the institutions, management reports, quality certification programs, use of indicators, adverse event reporting, discussion and publication of these indicators.

The data were collected between December 2010 and May 2012. For data analysis, the study variables were appropriately coded using double-entry in a Microsoft Excel database. The results were exported to Epi Info, version 3.5.2, and descriptive statistics were applied, considering the frequency at which they occurred, in accordance with the research objective.

Approval was obtained from the Research Ethics Committee at the University of São Paulo at Ribeirão Preto College of Nursing, under number 1279/11.

\section{Results and discussion}

Among the institutions under analysis, 64.8\% participated in quality programs. In the context of the 17 institutions, 36.4\% participated in the Commitment to Hospital Quality Program (CQH) which has 120 participating hospitals, and another 36.4\% hospitals were included in the Brazilian Accreditation Program (ONA) which has 184 participating hospitals ${ }^{\text {[19] }}$. Despite distinctions between them, both methodologies are guided by the same master concepts, quality and safety.

Quality certification and participation in the hospital accreditation program are voluntary processes in Brazil, intended to diagnose medical-hospital care delivery and process systemization, with a view to achieve improvements in service quality, and has expanded across Brazilian hospital institutions since the end of the 1990's ${ }^{[20]}$. 
In $94.1 \%$ of the hospitals, it was observed that the nursing service has adopted quality indicators, permitting the planning and implementation of care improvements. The indicators adopted are displayed in Table 2:

Table 2. Quality indicators in nursing services adopted by hospitals, Brazil 2012

\begin{tabular}{|c|c|c|c|c|}
\hline Quality indicators & $\mathbf{N}$ & Adopt (\%) & Do not adopt (\%) & Total (\%) \\
\hline Incidence of patient falls & 17 & 94.1 & 5.9 & 100 \\
\hline Incidence of accidental extubation & 17 & 70.6 & 29.4 & 100 \\
\hline Nasogastric tube loss & 17 & 82.4 & 17.6 & 100 \\
\hline Incidence of pressure ulcer & 17 & 76.5 & 23.5 & 100 \\
\hline Incidence of phlebitis & 17 & 70.6 & 29.4 & 100 \\
\hline Incidence of central venous catheter obstruction & 17 & 11.8 & 88.2 & 100 \\
\hline Incidence of error in medication administration & 17 & 58.8 & 41.2 & 100 \\
\hline Distribution of nurses per bed & 17 & 35.3 & 64.7 & 100 \\
\hline Distribution of nursing technicians and nursing assistant per bed & 17 & 35.3 & 64.7 & 100 \\
\hline Nursing absenteeism rate & 17 & 58.8 & 41.2 & 100 \\
\hline Nursing turnover rate & 17 & 52.9 & 47.1 & 100 \\
\hline Occupational accident rate among nursing professionals & 17 & 47.1 & 52.9 & 100 \\
\hline Hours of training for nursing professionals & 17 & 52.9 & 47.1 & 100 \\
\hline Client satisfaction with nursing & 17 & 47.1 & 52.9 & 100 \\
\hline Non-compliance in keeping nursing records & 17 & 23.5 & 76.5 & 100 \\
\hline
\end{tabular}

The choice of adoption indicators by nursing services reveals that the nurses typically prefer to evaluate the processes in health care, such as rates of falls, loss of nasogastric tube, accidental extubation, incidence of pressure ulcers and incidence of phlebitis.

Studies in Brazil that discuss the issue of the use of indicators in different contexts of nursing work reveal that the experiences of nurses regarding the use of indicators still need to be expanded. Among the works found, the indicators were related to nursing in neonatology, the postpartum period, pressure ulcers, adverse events, falls, absenteeism and turnover, extubation of patients, obstructions in catheters, among others mentioned in the studies ${ }^{[14,18]}$. In another study ${ }^{[21]}, 30$ nurses were interviewed and described hospital infection control, medication administration errors, rate of customer satisfaction, care in the prevention of phlebitis and fall prevention as very important indicators for assessing the quality of nursing services.

The quality of care is often evaluated from the perspective of structure and process by enabling nurses' information desired under in the context of nursing the Nursing, with little focus on the final evaluation of results, which implies analyzing results that are related to the work of all professionals involved in giving assistance ${ }^{[22,23]}$.

It is important to emphasize that that the knowledge, monitoring and analysis of these indicators should serve as a basis for the improvement of the nursing processes in hospital institutions, since they constitute critical points of the processes related to nursing care. Hospital administrators should use this information to make decisions about whether to implement quality improvement changes, for example, by increasing the amount of nursing staff, implementing new risk assessment procedures, or prevention protocols ${ }^{[24]}$. 
To assess management processes, indicators are used related to the distribution of nursing assistants, nursing technicians and baccalaureate nurses per bed. Only two indicators were observed in $35.3 \%$ of the hospitals. Concerning absenteeism, $58.8 \%$ collected this indicator. Team turnover and training are observed in 52.9\% and the indicator for occupational accidents in $47.1 \%$.

Nursing staff absenteeism is worrisome because it disrupts the service, creates dissatisfaction and work overload and, consequently, influences the quality of care provided to the client ${ }^{[25]}$. Similarly, a high rate of turnover of nursing staff can lead to insufficient human resources and difficulty in qualifying workers, causing a decline in the quality of the care.

Donabedian ${ }^{[3]}$ reports that, for the purpose of quality assessment, outcomes need to be assessed, which is a process that involves clients. Client satisfaction with nursing would thus be the most appropriate way to assess quality outcomes. In this study, however, it was observed that this is the case in $47.1 \%$ of the hospitals analyzed. In $5.9 \%$, this is accomplished by social services and, in another $5.9 \%$, by the ombudsman.

Non-compliance in nursing records is measured or assessed in $23.5 \%$ of the institutions. Nursing records are used in communication and legal processes, which makes low adherence levels to their assessment a source of concern.

Besides the indicators presented so far, $11.8 \%$ adopt other types of indicators, all related to care processes, such as: nipple trauma or crack rates in postpartum women (5.9\%); presence of companions during delivery; preoperative visit rate; and occurrence of dirty equipment during the inspection process. Burns at the Surgical Center (SC) are used by another $5.9 \%$ and yet another $5.9 \%$ use indicators related to the risk of deep vein thrombosis, rate of ventilation-associated pneumonia and care-complexity ranking.

Hospital institutions traditionally use production indicators related to the number of hospital beds ${ }^{[22]}$, but at the institutions under analysis, only one of the nursing services indicated one of these indicators, which is the bed replacement and renewal index, used by $5.9 \%$ for the purpose of service assessment.

The discussion regarding how to calculate the indicator formula was based on the formula proposed by the CQH ${ }^{[11]}$.

Regarding client satisfaction with nursing, the CQH does not adopt any formula. According to the study, 5.9\% of the hospitals that adopt this indicator adopt satisfaction surveys, and yet another $5.9 \%$ use quantitative surveys with a Likert scale, including the assessment criteria of excellent, good, bad, very bad and did not answer. Only $11.8 \%$ adopt formulae, which are: total number of satisfied clients during the period multiplied by 100/total investigated during the same period; and the ranking per area multiplied by 100/total number of questionnaires answered. In 17.6\%, the client satisfaction indicator with nursing is collected by social services, customer care service or through the ombudsman.

The CQH does not use the non-compliance indicator in nursing research ${ }^{[22]}$, which is, however, calculated in $11.8 \%$ of hospitals, where the following formulae are adopted: total cases of non-compliance with the item investigated multiplied by $100 /$ total compliance + cases of non-compliance with the same item; and the number of patient files complying multiplied by 100/total number of files analyzed.

In 5.9\%, to collect the indicators for incidence rate of patient falls, incidence of accidental extubation, nasogastric tube loss, incidence of non-compliance in medication administration, absenteeism rate in nursing, turnover rate in nursing and training hours for nursing professionals, specific forms are used to feed a database and produce reports every three and six months, and annual reports, depending on the indicator. Another 5.9\% calculate the indicators based on a specific system at the intensive care unit (ICU), which are: incidence rate of accidental extubation; incidence of pressure ulcers; central venous catheter obstruction; distribution of nurses per bed and distribution of nursing technicians and assistant nurses per bed. At the same institution, event graphs are used for patient falls and for the incidence rate of non-compliance with medication administration. 
In 5.9\% of the institutions under analysis, the formulae used to calculate the indicators were not revealed.

The CQH calculates the falls indicator through the relationship between the number of falls and the number of patients per day, multiplied by 1,000 . In $58.8 \%$ of the institutions, this formula was used, while $5.9 \%$ used patients per month. In another $11.8 \%$, the formulae adopted are different: number of events divided by total number of patients at risk; and the incidence of falls in the period divided by the total number of patients discharged from the unit.

As regards the accidental extubation indicator, the CQH formula is given by the relationship between the number of accidentally extubated patients and the number of intubated patients per day, multiplied by 100 . In $41.2 \%$ of the hospitals under analysis, this formula was adopted, while 5.9\% used absolute figures.

Concerning nasogastric tube loss, the $\mathrm{CQH}$ presents the following formula: number of cases of nasogastric tube loss divided by number of patients with nasogastric tubes per day, multiplied by 100 , used in $52.9 \%$ of the hospitals. In $5.9 \%$, the period was changed from day to month and, in another $5.9 \%$, the number of events is divided by the total number of patients using a nasogastric tube.

The following formula is given: number of new cases of patients with pressure ulcers in a given period divided by the number of people exposed to the risk of pressure ulcers during the same period, multiplied by 100, to calculate the incidence rate of pressure ulcers according to the CQH. This formula is adopted in $47.1 \%$ of the institutions. In another $11.8 \%$, the relationship between the number of events and the total number of patients at risk is used, in accordance with the Braden scale.

In regard to phlebitis, one of the institutions used absolute figures. The CQH formula is the relationship between the number of phlebitis cases during the period and the number of patients per day with peripheral venous access, multiplied by 100 , as observed in $52.9 \%$ of the institutions.

According to the $\mathrm{CQH}$, the incidence rate of central venous catheter obstruction is calculated by the total number of catheter obstruction cases during the period multiplied by 100, divided by the total number of patients per day using a catheter in the same period, adopted in $5.9 \%$ of the hospital under analysis.

Concerning the incidence of non-compliance in medication administration, the CQH formula is the relationship between the number of cases of non-compliance associated with medication administration and the number of patients per day with prescribed medication, multiplied by 100 , used in $29.4 \%$ of the hospitals under analysis, while $5.9 \%$ calculate the number of cases every month in absolute figures.

The CQH formula for the distribution of baccalaureate nurses, nursing technicians and nursing assistant per bed makes distinctions according to the complexity of care delivery. In $17.6 \%$ of the participating institutions, the distributions of baccalaureate nurses per bed and of nursing technicians and nursing assistant per bed are calculated. Yet another 5.9\% only use the distribution rate of nursing technicians and nursing assistant per bed, calculated through their own formula.

To calculate the absenteeism rate, $41.2 \%$ used the $\mathrm{CQH}$ formula, which is: number of man-hours absent divided by number of man-hours worked, multiplied by 100; 5.9\% used the Gaidzinski rate.

The CQH calculates the turnover rate in nursing as follows: the relationship between the number of admissions and dismissals divided by two and the mean number of employees, considering active professionals and workers on leave. Among the participating institutions, $47.1 \%$ adopted this formula.

To calculate the occupational accident rate among nursing professionals, the CQH formula corresponds to the relationship between the number of occupational accidents among nursing professionals and the number of active nursing team 
members. Among the participants, $11.8 \%$ adopted exactly the same formula, while $29.4 \%$ multiplied the result obtained by 100.

As regards the indicator hours of training for nursing professionals, the $\mathrm{CQH}$ presents the following formula: relationship between the sum of (number of employees who attended course 1 multiplied by the hour load of course 1) + (number of employees who attended course 2 multiplied by the hour load of course 2) + (Number of employees who attended course $n$ multiplied by the hour load of course $n$ ) and number of man-hours worked, multiplied by 1,000 . This formula was adopted in $23.5 \%$ of the hospitals studied.

In $88.2 \%$ of the hospitals, the indicators used by the nursing team are disseminated, while $5.9 \%$ do not disseminate indicators and another 5.9\% did not answer this item. To disseminate the data, different methods are used, including worksheets, graphs, Internet, meetings, notice boards in the specific unit and data show presentations. Also, $82.4 \%$ discuss the results obtained with their team. The discussions take place during meetings with the nurse supervisor, when interventions are determined to improve nursing actions, through benchmarking, meetings of the Technical Nursing Council, meetings with the Nurse Coordinator to multiply the information obtained, during shift transfers and in annual patient safety training programs.

\section{Conclusions}

The study objective was achieved to the extent that it revealed what quality assessment indicators are adopted in the institutions under analysis, which indicators are the most prevalent and the formulae adopted to calculate them. The study's limitations are the number of participating institutions and their representativeness in the context of Brazilian hospitals.

The least prevalent indicators are management indicators related to human resources and user satisfaction with the services, while the most prevalent ones were related to classical care processes. The importance of these management parameters should be emphasized to take into account standards of high quality, as the indicators are not exclusive.

For the purposes of calculation, the formulae of the Commitment to Hospital Quality Program tend to be adopted. Even at those hospitals that participate in quality or accreditation programs, however, other non-standardized or specific formulae are adopted, which makes it difficult to compare the indicators these institutions assess. Also regarding the comparison of indicators with other health services, institutional adherence levels to this practice are low.

The creation of a single database and the standardization of formulae may result in hospitals gaining the capacity to collect and use valid, reliable, and comparable nursing-sensitive quality indicator data to advance the potential for patient care benchmarking and support making evidence-based decisions within and between hospitals and health systems. Concerning adverse events, many hospitals report these events, with a trend to report those events that are most closely related to the nursing team's care processes.

For leaders, maintaining international quality and safety recommendations is a hard process, as it is difficult to determine what measures will significantly demonstrate that care delivery is both safe and effective. Therefore, it is important to develop a measurement system that monitors internal improvement opportunities and is in accordance with Brazilian and international measures ${ }^{[26]}$.

In conclusion, health institutions need to be encouraged to intensity their adoption of these and other new indicators, and not only in the hospital context. Among the hospitals that participate in quality and accreditation programs and use indicators, the creation of databases and their comparison and exchange with other services should be stimulated. In regard to adverse events, the analysis and reporting of events related to care processes other than nursing needs to be encouraged. 
Top quality will be achieved through better assessment of management and care processes, as well as through the implementation of changes and improvements, departing from the data collected in these processes.

\section{Acknowledgements and funding}

Acknowledgements to Foundation for Research Support of the State of São Paulo - FAPESP to source of funding in this study.

Carmen Silvia Gabriel: substantial contributions to conception and design, and acquisition of data, analysis and interpretation of data; involved in drafting the manuscript or revising it critically for important intellectual content; and final approval of the version to be published.

Silvana Silveira Kempfer: involved in drafting the manuscript and revising it critical for important intellectual content; and final approval of the version to be published.

Andrea Bernardes: substantial contributions to conception and design, and acquisition of data, analysis and interpretation of data; involved in drafting the manuscript or revising it critically for important intellectual content; and final approval of the version to be published.

Fernanda Ludmila Rossi Rocha: collection and organization of data.

Daniele Ramos: collection and organization of data.

Andrea Boldrini: collection and organization of data.

\section{References}

[1] Palmer RH, Donabedian A, Povar G. Reflections on the Effectiveness of Quality Assurance. In: RH Palmer, A Donabedian and GJ Povar. Striving For Quality in Health Care: An Inquiry into Policy and Practice. Ann Arbor, MI, Health Administration Press; 1991; 59-128. PMid:1954775

[2] Kurcgant P, Tronchin DMR, Melleiro MM. A construção de indicadores de qualidade para a avaliação de recursos humanos nos serviços de enfermagem: pressupostos teóricos. Acta Paul Enferm. 2006; 19(1):88-91.

http://dx.doi.org/10.1590/S0103-21002006000100014

[3] Donabedian A. The definition of quality and approaches to its assessment: explorations in quality: explorations in quality assessment and monitoring. Chicago: Health Administration Press; 1980; 1.

[4] Donabedian A. The quality of care. How can it be assessed? JAMA. 1988; 260(12):1743-48. PMid:3045356 http://dx.doi.org/10.1001/jama.1988.03410120089033

[5] Feldman LB, Gatto MAF, Cunha ICKO. História da evolução da qualidade hospitalar: dos padrões a acreditação. Acta Paul Enferm. 2005; 18(2):213-9. http://dx.doi.org/10.1590/S0103-21002005000200015

[6] Pomey MP et al. Does accreditation stimulate change? A study of the impact of the accreditation process on Canadian healthcare organizations. Implementation science [Internet]. 2010 [cited 2013 Jan 30]; 5(31). Available from: http://www.implementationscience.com/content/5/1/31.

[7] Portela MC et al. Estrutura e qualidade assistencial dos prestadores de serviços hospitalares à saúde suplementar no Brasil. Cad Saúde Pública. 2010; 26(2):399-408. PMid:20396855 http://dx.doi.org/10.1590/S0102-311X2010000200019

[8] Nicklin W. The Value and Impact of Health Care Accreditation : A Literature Review. Accreditation Canada [Internet]. 2012 [cited 2013 Jan 24]; 1-12. Available from: http://www.accreditation.ca/uploadedFiles/Value\%20of\%20Accreditation_EN.pdf.

[9] Joint Commission on a Accreditation Healthcare Organizations - JCAHO [Internet]. Standards revisions for 2008 [cited 2012 Jul 21]. Available from: http://www.jointcommission.org/Standards/.

[10] World Health Organization - WHO. Quality and accreditation in health care services - a global review. Geneva: WHO; 2003.

[11] Programa de Qualidade Hospitalar (PQH). Manual de Indicadores de Enfermagem NAGEH. São Paulo (SP): APM, CREMESP; 2012.

[12] Qualiy indicator Project. Maryland Hospital Association EUA [Internet]. [cited 2011 Mar 02]. Available from: http://www.qiproject.org/index.asp?cmd=general_info.

[13] Ministério da Saúde (Brasil). Secretaria de Assistência à saúde. Manual Brasileiro de Acreditação hospitalar. 3. ed. Brasília, DF. 2011.

[14] Simões e Silva C, Gabriel CS, Bernardes A, Évora YDM. Opinião do enfermeiro sobre indicadores que avaliam a qualidade na assistência de enfermagem. Rev Gaúcha Enferm. 2009; 30(2): 263-71. PMid:20027959 
[15] Polit DF, Beck CT, Hungler BP. Fundamentos da pesquisa em enfermagem: métodos, avaliação e utilização, 5.ed. Porto Alegre: Artmed 2004.

[16] Ministério da Saúde. Cadastro Nacional de Estabelecimento de Saúde [Internet]. 2012 [Acesso em: 04 de dezembro de 2012]. Disponível em: http://cnes.datasus.gov.br/Mod_Ind_Unidade.asp?VEstado=35\&VMund=00\&VUnid=07.

[17] Ministério da Saúde. Cadastro Nacional de Estabelecimento de Saúde [Internet]. 2012 [Acesso em: 04 de dezembro de 2012]. Disponível em: http://cnes.datasus.gov.br/Mod_Ind_Unidade.asp?VEstado=35\&VMund=00\&VUnid=05.

[18] Caldana $\mathrm{G}$ et al. Indicadores de desempenho em serviço de enfermagem hospitalar: revisão integrativa. Revista da rede de enfermagem do nordeste. 2011; 12(1):189-97.

[19] Organização Nacional de Acreditação (ONA) [Internet]. Programa Brasileiro de Acreditação. 2013[Acesso em: 07 de Maio de 2013]. Disponivel: http://www.ona.org.br/OrganizacoesCertificadas.

[20] Paim CRP; Ciconelli RM. Auditoria de avaliação da qualidade dos serviços de saúde. RAS 2007; 9(36):85-92.

[21] Cintra EA, Pinto AC, Sousa EO, Rosa EV, Lima IA, Rodrigues SO. Utilização de indicadores de qualidade para avaliação da assistência de enfermagem: opinião dos enfermeiros. J Health Sci Inst. 2010; 28(1):29-34.

[22] Gabriel CS, Mello MRAC, Bernardes A, Rocha FLR, Miguelacci T, Silva MLP. Use of performance indicators in the nursing service of a public hospital. Rev Latino-Am Enfermagem. 2011; 19(5): 1247-54. http://dx.doi.org/10.1590/S0104-11692011000500024

[23] Vituri DW, Matsuda LM. Content validation of quality indicators for nursing care evaluation. Rev Esc Enferm USP. 2009; 43(2):429-37. PMid:19655686 http://dx.doi.org/10.1590/S0080-62342009000200024

[24] Gajewski B J, J D Mahnken, Dunton N. Improving quality indicator report cards through Bayesian modeling. BMC Medical Research Methodology [Internet]. 2008 [cited 2013 May 07]; 8:77. Avaiable from: http://www.biomedcentral.com/1471-2288/8/77doi:10.1186/1471-2288-8-77.

[25] Silva DMPP da, Marziale MHP. Absenteeism of nursing workers from a university hospital. Rev.Latino-Am.Enfermagem [Internet]. 2000 [cited 2013 May 07]; 8(5):44-51. Available from: http://dx.doi.org/10.1590/S0104-11692000000500007. http://dx.doi.org/10.1590/S0104-11692000000500007

[26] Pyle K, Wavra T. Quality Indicators for Critical Care. AACN Advanced Critical Care 2007; 18(3): 229-243. PMid:18019513 http://dx.doi.org/10.1097/01.AACN.0000284422.48213.f9 